\title{
A tribute to Achim Trebst at the time of his doctor honoris causa, University of Düsseldorf
}

\author{
Heinrich Strotmann
}

(C) Springer Science+Business Media B.V. 2009

\begin{abstract}
On June 9, 2009, we celebrate the 80th birthday of Achim Trebst. I present below the "Tribute" (Laudatio) that I read on February 11, 2000 on the occasion of his receiving Doctor honoris causa of the Faculty of Mathematics and Natural Sciences of the Heinrich Heine University in Düsseldorf. The text below is a translation from the original German to English with minor editorial changes by Govindjee.
\end{abstract}

Keywords Chloroplast autonomy - Coenzyme F · DBMIB · Herbicides · Quinones

\section{The tribute}

I am delighted to be able to speak about Achim Trebst, an outstanding scientist and an esteemed colleague, on the occasion of the award of Doctor honoris causa of the Faculty of Mathematics and Natural Sciences of the Heinrich Heine University Düsseldorf. Achim Trebst, Professor emeritus of Plant Biochemistry of Ruhr University Bochum is one of the international celebrities in photosynthesis research. He has worked in this field for more than 40 years and contributed immensely to the international reputation of photosynthesis research in Germany. By now he has published 190 papers and he expects to publish 200 papers soon. This indicates that he is not going to rest but continue working in research after he became free from his obligations as university professor.

In addition to his activities as a researcher and teacher he took over important academic duties: as Dean, as a

H. Strotmann $(\bowtie)$

Kopernikusstr. 57, 40699 Erkrath, Germany

e-mail: strotman@uni-duesseldorf.de reviewer for science foundations and scientific journals, as a co-editor of several journals and editor of scientific books. Further, he organized several conferences and had been an advisor and a board member of several research institutions. He was a consultant of our young university when it was established in the 1960s. He built bridges between biologists and chemists and promoted a fruitful dialog between them.

Achim Trebst was born on the 9th of June 1929, in Zeitz, a small town located in the Thuringian-Saxonian frontier area, in the center of a triangle formed by the cities Leipzig, Jena and Chemnitz. When he was still a child, his family moved to Hanau; it is a Hessian town in the vicinity of Frankfurt. After high school (Abitur) he became an apprentice in a pharmacy. Several famous German scientists, like Justus von Liebig and Wilhelm Pfeffer, began their careers this way. Like these pioneers, Achim decided to quit pharmacy after 2 years and chose chemistry. He matriculated as a student of chemistry at the University of Heidelberg.

In the Chemical Institute where once the celebrated Robert Bunsen and August Kekulé were professors, Achim worked for a doctoral thesis in organic chemistry under the supervision of Professor Friedrich Weygand. This organic chemist was very much interested in biological chemistry. He worked on coenzymes, nucleic acids, peptides and glycosides; he investigated the mechanism of action of sulfonamides and was one of the first German researchers to use radioactive isotopes to investigate metabolic pathways in microorganisms. Achim Trebst's thesis was on "Biochemical investigation of coenzyme $\mathrm{F}$ in bacteria using ${ }^{14}$ C-labeled compounds." Coenzyme $F$ was the trivial name of $\mathrm{N}^{10}$-formyltetrahydrofolic acid. Achim obtained the degree of a Doctor of Natural Sciences in 1955. In the same year, he moved together with Weygand to the Technical University in Berlin, where he worked 
with him for another year. He was a co-author of several papers on the metabolism of nucleosides and related compounds. Weygand's group also included Adolf Wacker, Helmut Simon und Hans Grisebach, who all later on played important roles in German biochemistry.

Achim entered the field of photosynthesis in 1956 as a postdoc of Daniel I. Arnon at the University of California (UC), Berkeley. UC Berkeley was the world's capital of photosynthesis research with Melvin Calvin (who, in 1961, received a Nobel Prize) and Daniel Arnon as protagonists. Calvin and his associates, particularly Andrew Benson and James Bassham, succeeded in clarifying the $\mathrm{CO}_{2}$ fixation cycle ("Calvin-Benson Cycle"), the so-called "dark reactions" of photosynthesis. Arnon, on the other hand, made important discoveries on the "light reactions" of photosynthesis: photosynthetic electron transport, and more importantly, photophosphorylation. His findings led to the concept of cyclic and non-cyclic photophosphorylation. He was assisted by an international group of young researchers, among them were: F.R. Whatley, M.B. Allen, M. Losada and H.Y. Tsujimoto. Furthermore, Arnon was interested in finding out whether isolated chloroplasts can carry out the complete set of photosynthetic reactions, an open question then. Achim Trebst was involved in this problem and he verified the functional autonomy of the chloroplast by reconstituting a quasi-chloroplast system containing isolated thylakoids and soluble chloroplast extracts. The results were published in five papers, two of them in Nature.

In 1959 Achim returned to Weygand's laboratory, which had moved to the Technical University in Munich. Weygand permitted him to work independently on photosynthesis. In the following years, Achim worked and published on different aspects of photosynthesis, the most important ones concerning the role of quinones in photosynthetic electron transport. In 1962, Achim was promoted to "Privatdozent" and one year later he was appointed as Professor of Plant Biochemistry in the Institute of Plant Physiology in the University Götttingen. The head of the institute was the plant physiologist Professor André Pirson who worked on physiology of photosynthesis and related aspects, using unicellular green algae. Concerning nomination to the newly put up chair of plant biochemistry, Pirson had contacted Professor Kurt Mothes, a distinguished professor of plant biochemistry at the University Halle-then in the German Democratic Republic. Mothes suggested Achim Trebst as an excellent candidate, and Pirson accepted him. German research in biology had practically ceased by World War II. In the early 1960s, the research level slowly improved. Mothes and Pirson understood that in modern biology the cooperation of physicists, chemists and biologists was necessary. Young scientists, who had studied in leading laboratories in the
US, should take the lead in propagating new concepts and methods. Achim Trebst was one of them and he fulfilled this task with remarkable success.

Achim stayed in Göttingen for four productive years. He established a well equipped laboratory, initiated new research projects and attracted capable students. His students Hermann Bothe, Erich Elstner, Bernt Gerhard, Ahlert Schmidt and Herbert Böhme were later on appointed as professors in different German universities. Others obtained positions in the industry. Elfriede Pistorius, his technician, went to the US when he left Göttingen. She studied biology, got a $\mathrm{PhD}$ degree and after her return to Germany became a professor in the University of Bielefeld. With regard to Achim's private life Göttingen was a happy place, too. There he found his charming wife and his family flourished. His family includes four children, gifted physicists and physicians.

In 1967 Achim Trebst was nominated to the Chair of Plant Biochemistry at the newly established Ruhr University in Bochum. During the following 30 years, his institute developed to become a widely recognized center of photosynthesis research and bioenergetics. Numerous scientists from all over the world came as guest speakers, guest professors and postdocs. Among his assistants were Peter Böger, Günter Hauska, Wolfgang Haehnel, Richard Berzborn, Walter Oettmeier, Jens-Dirk Schwenn, Günter Wildner and Udo Johanningmeier. They are university professors spread over the whole country-some of them already retired. The number of capable scientists brought forth by Achim Trebst, is really amazing. A position of associate professor was under the responsibility of Achim's chair, too. He hired Rudolf Thauer, a capable young microbiologist working on bioenergetics; after a few years, Thauer became a professor in Marburg and Head of the Max-Planck-Institute for Terrestrial Microbiology in the same town. His successor in Bochum was the microbiologist Karl-Heinz Altendorf. For him this position was a "spring board" to become the Head of Microbiology at the University of Osnabrück.

Already in the early 1960s, Achim was in contact with scientists working in the chemical industry, particularly in the Bayer company. A group of excellent chemists, among them Karl-Heinz Büchel and Wilfried Draber, had established a division of herbicide research in the Bayer company in Wuppertal. The photosynthetic apparatus was considered to be the most promising target of herbicides. Achim Trebst, as the German expert in the field of photosynthesis, was the ideal partner of the industry chemists. A long lasting fruitful collaboration began between them. Careful structure-function relationship analyses on the one hand gave important hints for new syntheses to the chemists, and on the other hand, several new inhibitors of photosynthesis permitted new important insights into the 
mechanism of photosynthesis. For photosynthesis research, the most successful compound (which never became a commercial herbicide) was the benzoquinone derivative DBMIB (2,5-dibromo-3-methyl-6-isopropyl- $p$-benoquinone $=$ dibromothymoquinone). It may not be much of an exaggeration to state that some time or other every photosynthesis researcher must have employed it. DBMIB was a new type of inhibitor, inhibiting photosynthetic electron transport at the oxidizing side of plastoquinone. By means of this inhibitor a series of unsolved questions of the mechanism of electron transport between the two photosystems could be answered. The basic paper [A. Trebst, E. Hart and W. Draber (1970) On a new inhibitor of photosynthetic electron transport. Z. Naturforsch. 25b, 1157-1159] was cited innumerable times.

In his research career, Achim returned to the quinones again and again. And he was right: quinones (ubiquinone, plastoquinone) are known to play a particularly important role in energy conservation since Peter Mitchell proposed the well-known chemiosmotic hypothesis. Achim and his associate Günter Hauska were among those who verified chemiosmosis and established the concept of vectorial electron transport by plain, but clear and conclusive experiments.

Achim Trebst had realized the potential of molecular genetics in understanding photosynthesis and bioenergetics. He was interested in sequences rather than genetics itself. Owing to molecular genetics, amino acid sequences were now easily available. He was fascinated by the possibility of finding the clue to molecular mechanisms of proteins by inspection of the structures. Since no three dimensional structures were known yet, Achim attempted to imaginebased on primary structures-three dimensional structures of catalytic centers. This work was a highly satisfying 'game', as well as an intellectual challenge. In this context, intensive collaboration with William Cramer must be mentioned. I remember a seminar in 1986 where Achim presented a model made of metal rods, showing the possible three dimensional structure of the catalytic part of the cytochrome $\mathrm{b} / \mathrm{f}$ complex that included the presumed location of the heme groups. By means of this model, he predicted a convincing mechanism of electron transport within this complex. Nowadays, since three dimensional structures at atomic resolution are available, we may be surprised to notice how good his predictions were.

Amazingly, the chemist Trebst also contributed to evolution, the classical field of biologists. He was the first to point to the molecular relationship between the photosynthetic cytochrome b/f complex and the mitochondrial b/c complex and he emphasized the molecular relationship between Photosystem II of plants and the photosystem of purple bacteria. This finding taught us that evolution is an economical process. Innovations often originate just by new combination of 'approved' elements.
A logical mind, imagination and intuition are important attributes of a great scientist. Achim Trebst possesses a lot of them. These qualities enabled him to accomplish a significant scientific opus. Moreover Achim donated his wonderful gifts to others, taught and inspired them. He discusses scientific issues with intellectual sharpness, but always within the rules of fairness. Decency is a self-evident attitude of Achim.

Achim Trebst was and is an esteemed guest in many universities and research institutions around the world. Often he is in Sweden (Stockholm), USA (Berkeley; Lafayette) and in Israel (the Weizmann Institute in Rehovot, the Hebrew University in Jerusalem, the Desert Research Institute in Sde Boqer). For him the friendship with Israeli colleagues is of special significance. Once, in a small symposium in Bochum, he introduced Itzhak Ohad from Jerusalem and himself as the "special pair". Photosynthesis people know the meaning of special pair. Here, we were also reminded of the fruitful period of Jewish and non-Jewish German collaboration in science before it was brutally terminated. Achim suffers from this cruel period of German history. His numerous visits to Israel somehow express his wish to revive relationships of past better times.

Achim Trebst has received several honors. In 1983, he was elected as member of the Rhenish-Westphalian Academy of Sciences. Already since 1974, he has been a member of the German Academy of Natural Scientists Leopoldina. This institution in Halle, founded in 1652 withstood all attempts of political manipulation and stayed an all-German island during the division of Germany, 1945-1990. Achim helped to ease the results of division of the country by visits, material and academic support.

Achim has received honorary doctorate degrees from abroad, the University of Stockholm (1990) and the Purdue University in Lafayette (1991). The Heinrich Heine University is the first German University to confer an honorary doctorate degree to him. Our faculty is honoring a great scientist and is repaying his abundant support and advice. He has consulted with the faculty in the conception and the organization of the Department of Biology which, we all think, was very well done. He has assisted in nominations and habilitations, and advised on research projects; he has collaborated and published with colleagues of our faculty.

Sincerity and modesty are qualities of his character that make him likable. For many of us he is a model of scientific and human qualities. He is a friend who motivates, encourages, inspires, appreciates, sometimes criticizes and always finds the right words.

Acknowledgment The above translation of my text was edited by Govindjee who had invited me to print this Tribute, in Photosynthesis Research, to Achim Trebst at his 80th birthday. 